\title{
New Algorithms and Their Application for Satellite Remote Sensing of Surface PM2.5 and Aerosol Absorption
}

R.-M. Hu, R.S. Sokhi,

Centre for Atmospheric and Instrumentation Research (CAIR), University of Hertfordshire, College Lane, Hatfield, AL109AB, UK.

and B. Fisher

Risk and Forecasting, Environment Agency, Kings Meadow Road, Reading, RG18DQ, UK.

Short title: SATELLITE REMOTE SENSING OF AEROSOLS 
Abstract. Estimation of Particulate Matter (PM) concentration and aerosol absorption is very important in air quality and climate studies. To date, smoke, mineral dust and anthropogenic pollutants are most uncertain aerosol components in their optical and microphysical properties. In this study, we retrieve the PM2.5 and Absorbing Aerosol Optical Depth (AAOD) from the Total Ozone Mapping Spectrometer (TOMS), the Moderate Resolution Imaging SpectroRadiometer (MODIS) and the Multiangle Imaging SpectroRadiameter (MISR) measurements. A global chemical transport model (GEOS-CHEM) is used to simulate the vertical profiles of PM2.5 and AAOD. We find the 2003 heat wave has strong impact on PM2.5 across Europe and increased average 18 percent of PM2.5 concentration. The aerosol species with the largest concentration increase are ammonium nitrate, black carbon and mineral dust. The Aerosol Robotic Network (AERONET) measurements have been used to validate our retrieval of AAOD. We find that there is a significant agreement between AERONET measurements and our retrievals with the correlation coefficient, slope and intercept of $0.91,0.99$ and 0.001 respectively. The absorbing aerosols can exert negative health effect, increase positive aerosol radiative forcing and contribute positive aerosol-climate feedbacks. 


\section{Introduction}

Atmospheric aerosols have a significant effect on human health (Dockery et al., 1993; Pope et al., 1995) and on regional and global climate changes (Hansen et al., 1998; Ramanathan et al., 2007). To date, the information of aerosol size distribution and chemical composition is still limited. In order to improve our understanding of the causes, impacts and control of particulate matter pollution, which affects many regions of the world, the detailed knowledge of aerosol properties is essential for the emission reduction and air quality monitoring.

Epidemilogical studies reveal that fine particulate matter with diameter smaller than 2.5 $\mu \mathrm{m}$ (PM2.5) has adverse health effects including asthmatic symptoms, pulmonary inflammation, cardiopulmonary mortality, and lung cancers (Atkinson et al., 2001; Anderson et al., 2002; Pope et al., 2002). Particle chemical compositions have also been associated with high risks of human health. Increasing data on air quality monitoring shows that many toxic aerosol species accumulate in fine particles size. This fraction of particles have higher oxidative stress potential and can penetrate and destroy mitochrodra with epithelial cells (Li et al., 2003). As aerosols have a direct relevance to air quality and health effect, it is important to quantify the optical and microphysical properties of fine and ultra fine particles.

Remote sensing measurements have provided a good opportunity to detect the source and monitor the transport and evolution of aerosols released from biomass burning and dust storms. The Moderate Resolution Imaging Spectrometer (MODIS) and the Multiangle Imaging Spectroradiometer (MISR) instruments have been operated on board the Terra satellite since December 1999. Aerosol optical depth can be determined from MODIS and MISR measurements over ocean and most of land surfaces (King et al., 1992; Kaufman et al., 1997; Tanre et al., 1997; Diner et al., 1997; Kahn et al., 2005) through observations at visible and infrared wavelengths. The Total Ozone Mapping Spectrometer (TOMS) aerosol index at the ultraviolet wavelength is sensitive to absorbing aerosols so that it can be used to detect the cabonaceous and dust particles (Herman et al., 1997; Torres et al., 1998). The relationship between column Aerosol Optical Depth(AOD) and surface PM2.5 has been explored over 
United States using satellite AOD data (Wang and Christopher, 2003; Liu et al., 2005). They find that MODIS or MISR AOD has good correlations with hourly or monthly PM2.5 measurements. However, the relationship is simply empirical due to complicated dependence on several factors such as aerosol chemical composition, size distribution, aerosol profile and atmospheric conditions. The application of satellite observations in assessing the particulate matter for mega cities such as Mexico City, Delhi, Hong Kong and New York has also been shown to be promising (Gupta et al., 2006; Massie et al., 2006). High correlation between the daily mean AOD from satellite and ground measurements indicates that satellite observations can be used to detect the heavy pollution episodes such as mega city haze, forest fires and dust storms. Koelemeijer et al. [2006] detected an increase in AOD over Europe using MODIS data during summer of 2003. The question remains: How much does the average PM2.5 concentration increase due to the anomalous heat wave of 2003 ? Which kinds of aerosol species make a large contribution to the increase of PM2.5? What kind of interaction between air quality and climate change ? Here, we use AOD and size information from satellite data and aerosol profiles from GEOS-CHEM to derive the surface PM2.5 concentrations. Futhermore, we use our recently developed retrieval algorithm for aerosol single scattering albedo (Hu et al., 2007) to calculate the Absorbing Aerosol Optical Depth (AAOD).

\section{Methodology}

Suspended Paticulate Matter (PM) is complicated by virtue of its chemical composition, size distribution and particle shape. Air quality standards have been expressed in terms of particles mass concentration as PM2.5 or PM10 which represents particles of aerodynamic size of $2.5 \mu \mathrm{m}$ and $10 \mu \mathrm{m}$ respectively. Two common approaches have been currently used to represent the particles size: the modal and sectional approaches (Zhang et al., 2004). For modal approach, the particle size distribution is assumed to be composed of several lognormal modes: 


$$
n_{j}(r)=\frac{N_{j}}{\sqrt{2 \pi} \ln \sigma_{g, j}} \frac{1}{r} \exp \left[-\frac{\left(\ln r-\ln r_{g, j}\right)^{2}}{2\left(\ln \sigma_{g, j}\right)^{2}}\right]
$$

where $N_{j}$ is a normalizing constant(in $\mathrm{cm}^{-3}$ ); $r$ is the radius; $\log \sigma_{g, j}$ is the geometric standard deviation. $r_{g, j}$ is the geometric mean radius.

For each aerosol type, the aerosol optical depth can be computed at wavelength $\lambda$ as follows:

$$
\tau_{j}(\lambda)=\int_{z_{1}}^{z_{2}} \int_{r_{\min }}^{r_{\max }} Q_{e}(x, m) \pi r^{2} n_{j}(r) d r d z
$$

Where $Q_{e}$ is the extinction efficiency with size parameter $x$ and refractive indices $m$. $z$ is the altitude. For non-spherical particles, size parameter $x_{e f f}=2 \pi r_{e f f} / \lambda$. The effective radius $r_{\text {eff }}$ is defined as the ratio of the third to second moment of aerosol size distribution (Hansen and Travis, 1974):

$$
r_{e f f, j}=\int_{r_{\min }}^{r_{\max }} n_{j}(r) r^{3} d r / \int_{r_{\min }}^{r_{\max }} n_{j}(r) r^{2} d r
$$

Then the mass concentration between the ground and altitude $z$ can be expressed as

$$
M_{j}\left(r_{l}, z\right)=4 \rho r_{e f f, j} \tau_{j} f /\left(3 Q_{j}^{e x t} z\right)
$$

Where $r_{l}$ is the selected radius upper limit for aerosol size distribution such as $1.25 \mu \mathrm{m}$ for PM2.5 or $5 \mu \mathrm{m}$ for PM10. $\rho$ is the aerosol density and $Q_{j}^{e x t}$ is the average column extinction efficiency. $f$ is the fraction of optical depth below altitude $z$. The values of $f, r_{\text {eff }, j}$ and $z$ are selected from GEOS-CHEM model with validation from ground-based and air-based measurements. The effective radius is related to aerosol size, shape, mixing state and hygroscopicity. We use the calculated relationships to interpret the satellite retrievals of $r_{e f f, j}$ and alternatively employ in situ measurements of aerosol optical and microphysical properties to calibrate the effective radius for specific uses. We assume the uniform aerosol properties between the surface and altitude $z$. The total aerosol mass concentration for external mixture can be calculated using the sum of those component aerosols such as sulfate, nitrate, ammonium, black carbon, organics, dust and sea salt. The extinction efficiency is calculated by Mie 
theory for spherical particles. For non-spherical particles, we use T-Matrix method (Mishchenko, 1995) to calculate the extinction efficiency and effective radius. We use AOD data from MODIS over ocean and MISR over land. The detailed microphysical and optical properties of major aerosol components used in this study are given in Table 1.

The vertical profiles of aerosol species are generated from GEOS-CHEM model (Bey et al., 2001; Jacob et al., 2003; Park et al., 2003). The total AOD simulated from GEOS-CHEM is scaled to match the satellite AOD with the scaling being applied equally to all species. Then we use the GEOS-CHEM vertical profiles and satellite AOD to retrieve PM2.5 concentration at the surface. The model is driven by assimilated meteorological data from the Goddard Earth Observing System (GEOS-3) at the NASA Global Modeling and Assimilation Office (GMAO). Aerosol simulation includes the sulfate-nitrate-ammonium system, black carbon, primary organics, secondary organics, mineral dust, and sea salt. The mineral dust simulation is based on the Dust Entrainment and Deposition (DEAD) scheme of Zender et al. [2003] and the Global Ozone Chemistry Aerosol Radiation and Transport (GOCART) model scheme (Ginoux, et al., 2001) as implemented by Fairlie et al. [2006]. The size distribution of aerosols which could be adjusted is assumed to be lognormal with the mean radius and the standard deviation used in GEOS-CHEM (Martin et al., 2003).

In order to estimate the aerosol absorption, we retrieve the aerosol single scattering albedo that reproduces the TOMS aerosol index, when constrained by MODIS and MISR aerosol optical depth and by relative vertical profiles from a global chemical transport model (GEOS-CHEM) (Hu et al., 2007). We use MISR AOD instead of MODIS AOD over most deserts or snow/ice regions due to high surface reflectivity. The vertical profiles of aerosol species such as sulphate, black carbon, sea salt, dust and organics are taken from GEOS-CHEM model simulations in order to consider the height of aerosol plume. The total backscatter radiance is calculated by the vector discrete ordinate radiative transfer model VLIDORT (with polarization) (Spurr, 2002; Natraj et al., 2007). We adjust the aerosol single scattering albedo using MODIS/MISR AOD and size retrieval until the TOMS aerosol index is matched. The retrieval aerosol single scattering albedo has been validated with measurements 
from the Aerosol Robotic Network (AERONET). We find the Angstrom exponent and aerosol optical depth make the largest contribution to the retrieval uncertainty. Our total retrieval uncertainty of single scattering albedo is 10-15 percent. We provide absorbing aerosol optical depth (AAOD) rather than single scattering albedo since the AAOD is less sensitive to cloud contamination and aerosol humidification (Kaufman et al., 2006). The AAOD at wavelength $\lambda$ is calculated by

$$
\tau_{a}(\lambda)=\tau_{e}(\lambda)\left(1-\omega_{0}(\lambda)\right)
$$

Where $\tau_{e}$ and $\tau_{a}$ are aerosol optical depth and aerosol absobing optical depth respectively.

\section{Results}

Figure 1 shows the PM2.5 concentration retrieved from MODIS and MISR data, when constrained by vertical profiles of PM2.5 from GEOS-CHEM. High values of PM2.5 are found over Eastern Europe, Eastern United States, and surrounding areas of Saharian region, associated with biomass burning, industrial pollution and dust storms. The retrieved PM2.5 reaches a seasonal maximum over Europe during summer when strong heat wave occurred over Spain, France, Germany and Italy. The intense fires occurred in southern Europe (i.e., France, Spain, and Portugal) sweeping through 5.6 percent of the national forest area and causing about 1 billion euros losses. The high values of PM2.5 are found over Mediterranean sea which indicate the significant aerosols transported from forest fires, anthropogenic emissions and dust storms. The extreme events such as heat wave and drought have the potential to cause poor air quality, affect the human health (Bono et al., 2004) and erode the ecosystem productivity, reverse carbon sinks to sources and contribute to positive carbon-climate feedbacks (Ciais et al., 2005).

Figure 2 presents the inter-comparison of PM 2.5 daily mean between measurements at Melpitz, Germany, GEOS-CHEM model simulations and our retrievals. We find our retrievals have improved the results from GEOS-CHEM model simulation. The retrieval results show significant agreement with the PM2.5 daily mean from the ground measurements with the correlation coefficient, slope and intercept 
$0.83,0.51$ and 9.54 respectively. The statistical calculation is performed by organic regression method (Hirsh and Gilroy, 1984). However, the retrievals do not capture well the highest value of PM2.5 which are likely to be contributed by strong local emission sources. Due to the limited resolution of our model simulations and satellite measurements, we have to use spatial and temporal interpolation to get the PM2.5 values for some site. This is one of reasons that we underestimate the peak values. To improve the agreement, much higher resolution of model simulations and satellite observations is required to better capture this kind of daily variation. Figure 3 presents more validation results from other measurement sites such as Neuglobsow, Deuselbach, Waldhof, H-Linden in Germany. We find our retrievals have a significant agreement with ground measurements aside from the peak values of PM2.5.

Figure 4 presents the PM2.5 concentration in August at Schauinsland, Germany for year 2002, 2003 and 2004. The monthly mean values of PM2.5 concentration in 2002, 2003 and 2004 are 8.5, 20.5 and $8.9 \mu \mathrm{g} / \mathrm{m} 3$ respectively. We find there is a significant increase of PM2.5 concentration during strong heat wave of 2003 over Europe. Most available measurements in August 2003 and 2004 at European sites have been investigated (not shown here). The average increase of the PM2.5 is 18 percent due to impact of the 2003 heat wave from our retrievals in August 2003 and 2004. In order to further understand the individual contributions of aerosol species to PM2.5, we have analyzed the individual aerosol component from our retrievals in August 2003 and 2004. Figure 5 presents the contribution of aerosol species to PM2.5 at the Schauinsland, Germany. The concentrations of ammonium nitrate, back carbon and dust in August 2003 are significantly higher than in August 2004. We find the strong point emission sources during heat wave of 2003. Major local emission sources (e.g. power generation, domestic consumption and industrial processes) can significantly contribute to high level of air pollution during hot days. Furthermore, there are evidences from satellite observation to indicate that the long range transport of smoke, mineral dust and anthropogenic aerosols from biomass burning, dust storms and industrial pollution episodes can strongly affect surface air quality. These aerosol species are harmful to human health. The increasing of black carbon and dust particles can also enhance the solar absorption and lead to local and regional climate change. Obviously, further analysis of interactions 
between regional air quality and climate change is of great interest.

Figure 6 presents the AAOD derived from MODIS aerosol optical depth and our retrieved aerosol single scattering albedo. Obviously, the absorbing aerosols are found in the desert and biomass-burning regions. The seasonal variation of AAOD over Atlantic Ocean is mostly driven by dust storms. High values of AAOD are seen over Europe and Atlantic Ocean during spring and summer. The enhancement of AAOD over Europe is the clear evidence that the Sahara dust particles are transported to most parts of Europe.

We use measurements from AERONET (Aerosol Robotic Network) (Holben et al., 1998; Dubovik et al., 2002) sites to validate our retrieval results. AERONET consists of more than 180 Sun and sky scanning radiometers at ground sites throughout the world. A filter wheel allows measurements in up to 8 spectral bands, typically centered at $0.34,0.38,0.44,0.56,0.67,0.87,0.94$, and $1.02 \mu \mathrm{m}$. The theoretical inversion scheme (Dubovik et al., 1998) is realized in the algorithm of retrieving aerosol single scattering albedo from the spectral measurements of direct and diffuse radiations by using a radiative transfer code which accounts for multiple scattering (Nakajima et al., 1983). The accuracy expected is 10-15 percent. We use coincident measurements of the Level 2 data for inter-comparison. Figure 7 shows the inter-comparison of AAOD between AERONET measurements and our retrievals. We find our retrieved AAOD is in significant agreement with AERONET when AAOD is large. For smaller AAOD, the retrieval appears to overestimate the aerosol absorption. The correlation coefficient, slope and intercept are $0.91,0.99$ and 0.001 respectively.

Our retrievals slightly overestimate the absorbing aerosols transported to Europe (see Figure 4). The discrepancy probably stems from a number of factors including emission sources, chemical mixing, and dust or smoke deposition in the model simulations. Uncertainties also exist in aerosol size distribution, refractive indices and mixing state for calculation of AAOD. The strong spatial and temporal variations of physical, chemical and optical properties of smoke and mineral particles are highly challenging for model simulations. The results show that the Saharian dust pollutants can be transported across the Mediterranean sea and reach most parts of Europe although discrepancy between 
model simulation and satellite observation still exists. The enhancement of AAOD in the Atlantic Ocean due to dust storm could lead to increase in the direct and indirect radiative forcing and change the sea surface temperature. On the other hand, the dust ion fertilization could enhance particulate organic carbon and increase the chlorophyll use efficiency in the Ocean (Bishop et al., 2002). This process could influence carbon cycle and regulate the atmospheric CO2. Meanwhile, the enhancement of oceanic carbon biomass could affect in-water and atmospheric radiation field and influence the backscattered radiance measured by satellite instruments (Hu et al., 2007). Furthermore, the rapid growth of world economy and the increasing greenhouse gases in the atmosphere could enhance the biomass burning and desertification. Concequently, more smoke and dust particles are expected to spread over Europe and North America during the outbreak of forest fires and dust storms, and change the local and regional climate and air quality.

\section{Conclusions}

We developed a method to retrieve the PM2.5 from MODIS/MISR satellite measurements. In order to reduce uncertainties in satellite retrievals of aerosol properties, we use a global chemical transport model (GEOS-CHEM) to generate the information of aerosol composition, size distribution and vertical profiles relative to retrievals of PM2.5. Our results reveal that high values of PM2.5 occur over most parts of Eastern Europe, Eastern United States, and surrounding areas of Saharian region, associated with biomass burning, industrial pollution and dust storms. The value of PM2.5 reaches seasonal maximum during summer of 2003 over Europe due to the strong heat wave. We have compared our retrievals with surface PM2.5 measured at Melpitz, Neuglobsow, Deuselbach, Waldhof, H-Linden and Schauinsland in Germany. There is a significant agreement between our retrievals and the in situ measurements aside from few days. The 2003 heat wave has strong impact on PM2.5 across Europe and increased average 18 percent of PM2.5 concentration in comparison with the same period of 2004 . The aerosol species with the greatest concentration increase are ammonium nitrate, black carbon and mineral dust. 
The AAOD has been calculated from the retrieved aerosol single scattering albedo and AOD from MODIS/MISR. We find the high value of AAOD over Europe is contributed significantly by emission sources from the forest fires, anthropogenic haze and long range transport of dust storms. The AAOD also reaches seasonal maximum across the Atlantic Ocean due to Saharian dust storms. The increase of AAOD could enhance the solar absorption and accelerate the warming trend caused by emission of greenhouse gases (Ramanathan et al., 2007). Our results have been validated by the AERONET AAOD. The significant agreement between AERONET AAOD and our retrievals with high correlation indicates the AAOD is less affected by cloud contamination and aerosol hygroscopicity. A slight overestimation of small AAOD is due to the uncertainties of emission sources, chemical mixing, and dust or smoke depositions in model simulations. The uncertainties of particle chemical composition, size distribution and mixing state are main sources of retrieval uncertainties.

Considering current operational retrieval algorithms for aerosol properties, we believe the advanced Chemical Transport Models (CTMs) with detailed chemical species, size information and vertical profiles can improve significantly the satellite retieval products. Coupling the Regional Multi-scale Air Quality Model with a global model will help to resolve the atmospheric processes on fine scales and will be useful for prediction of air quality on local and urban scales. This study demonstrates the advantages of integrating satellite remote sensing data with global models to shed light on monitoring the present and predicting the future air quality and climate change. 


\section{Acknowledgments.}

We would like to thank the scientists and managers for making the TOMS, MODIS, MISR and AERONET data publicly available. We are grateful for Bob Yantosca for computational assistance and Prof. Daniel Jacob for support. This work was supported by the U.K. Natural Environment Research Council as part of Mesoscale Modelling for Air Pollution Application Network (MESONET) and the U.K. Environment Agency of Comparison of Simple and Advanced Regional Models (CREMO) project. The GEOS-CHEM model is managed by the Atmospheric Chemistry Modelling group at Harvard University with support from the NASA Atmospheric Chemistry Modelling and Analysis Program. This work also feeds into the European COST728 Action on Enhancing Mesoscale Modelling Capabilities for Air Pollution and Dispersion Applications. 


\section{References}

Anderson, R.R., Martello, D.V., Rohar, P.C., et al., Sources and Composition of PM2.5 at the National Energy Technology Laboratory in Pittsburgh during July and August 2002, Energy and Fuels, 16, 261269, 2002.

Atkinson, R. W., Acute effects of particulate air pollution on respiratory admission, Am.J.Respir.Crit.Care.Med., 164, 1860-1866, 2001.

Bey I., D. J. Jacob, J. A. Logan, R. M. Yantosca, Asian chemical outflow to the Pacific: origins, pathways and budgets, J. Geophys. Res., 106, 23,097-23,114, 2001.

Bishop J. K. B., R. E. Davis and J. T. Sherman, Robotic observations of dust storm enhancement of carbon biomass in the North Pacific, Science, 298, 817-821, 2002.

Bono, A.D., Giuliani, G., Kluser, S., and Peduzzi, P., Impacts of summer 2003 heat wave in Europe, Environment Alert Bulletin, UNEP, 2, 1-4, 2004.

Ciais, P., Reichstein, M., Viovy, N. Granier, et al., Europe-wide reduction in primary productivity caused by the heat and drought in 2003, Nature, 437, 529-533, 2005.

Fairlie, T. D., D. J. Jacob and R. J. Park, The impact of transpacific transport of mineral dust in the United States, submitted to Atmos. Environ., 2006.

Diner, D., et al., Multi-angle Imaging Spectroradiometer (MISR) instrument description and experiment overview, IEEE Trans. Geosci. Remote Ses., 36(4), 1072-1087, 1998.

Dockery, D., C. Pope, X. Xu, J. Sprengler, J. Ware, M. Fay, B. Ferris, and F. Speizer, An association between air pollution and mortality in six US cities, N. Engl. J. Med., 329, $17531759,1993$.

Dubovik, O., B.N. Holben, Y.J. Kaufman, M. Yamasoe, A. Smirnov, D. Tanre, and I. Slutsker, Single-scattering albedo of smoke retrieved from the sky radiance and solar 
transmittance measured from ground. J. Geophys. Res., 103, 31,903-31923, 1998.

Dubovik, O., B.N. Holben, T.F. Eck, A. Smirnov, Y.J. Kaufman, D. Tanre, and I. Slutsker, Variability of absorption and optical properties of key aerosol types observed in worldwide locations, J. Atmos. Sci., 59, 590-608, 2002.

Ginoux, P., M. Chin, I. Tegen, J. Prospero, B. Holben, O. Dubovik, and S.-J. Lin, Sources and distributions of dust aerosols simulated with the GOCART model, J. Geophys. Res., 106, 20,555-20,273, 2001.

Gupta, P., S.A. Christopher, J. Wang, etal., Satellite remote sensing of particulate matter and air quality assessment over global cities, Atmospheric Environment, 40, 58805892, 2006.

Massie, S.T., J.C.Gille, D.P.,Edwards, S. Nandi, Satellite observations of aerosol and CO over Mexico City, Atmospheric Environment, 40, 60196031, 2006.

Hansen, J.E., and L.D. Travis, Light scattering in planetary atmospheres, Space Sci. Rev., 16, 527-610, 1974.

Hansen, J.E., M. Sato, A. Lacis, R. Ruedy, I. Tegen, and E. Matthews, Climate forcings in the Industrial era, Proc. Natl. Acad. Sci., 95, 12753-12758, 1998.

Herman, J.R., P.K. Bhartia, O. Torres, C. Hsu, C. Seftor, and E. Celarier, Global distribution of ultraviolet-absorbing aerosols from Nimbus 7-TOMS data, J. Geophys. Res., 102, 16911-16922, 1997.

Hirsh R. M. and E.J. Gilroy, Methods of fitting a straight line to data: examples in water resources. Water Res. Bull., 20, 705-711, 1984.

Holben, B.N. et al., AERONET - a federated instrument network and data archive for aerosol characterization. Remo. Sens. Environ., 66, 1-16, 1998.

Hu, R.-M., and R.S. Sokhi, Oceanic phytoplankton, atmospheric aerosol and Raman scattering 
impacts on space-based ultraviolet radiance Measurements, Atmos. Chem. Phys. Discuss., 7, 1435114367, 2007

Hu, R.-M., R.V., Martin, and T. D. Fairlie, Global retrieval of columnar aerosol single scattering albedo from space-based observations, J. Geophys. Res., 112, D02204, doi:10.1029/2005JD006832, 2007.

Jacob, D. J., J. H. Crawford, M. M. Kleb, V. S. Connors, R. J. Bendura, J. L. Raper, G. W. Sachse, J. C. Gille, L. Emmons, and C. L. Heald, Transport and Chemical Evolution over the Pacific (TRACE-P) aircraft mission: Design, execution, and first results, $J$. Geophys. Res., 108(D20), 9000, doi:10.1029/2002JD003276, 2003.

Kahn, R., et al., Multiangle Imaging Spectroradiometer (MISR) global aerosol optical depth validation based on 2 years of coincident Aerosol Robotic Network (AERONET) observations J. Geophys. Res., 110, D10S04, doi:10.1029/2004JD004706, 2005.

Kaufman, Y.J., D.Tanre, L.A. Remer, E.F. Vermote, A. Chu, and B.N. Holben, Operational remote sensing of tropospheric aerosol over land from EOS moderate resolution imaging spectroradiometer, J. Geophys. Res., 102, 17051-17067, 1997.

Kaufman, Y.J., I. Koren, Smoke and pollution aerosol effect on cloud cover, Science, 313, 655-658, 2006.

King, M.D., et al., Remote sensing of cloud, aerosol and water vapor properties from moderate resolution imaging spectrometer (MODIS), IEEE Trans. Geosci. Remote.Sens., vol.30, 2-27, 1992 .

Koelemeijer, R.B.A., C.D. Homan, J. Matthijse, Comparison of spatial and temporal variations of aerosol optical thickness and particulate matter over Europe, Atmospheric Environment, 40, 5304-5315, 2006. 
Li, N., M., Hao, R.F. Phaden, W.C. Hinds and A.E. Nel, Particulate air pollutants and asthma A paradigm for the role of oxidative stress in PM-induced adverse health effects, Clinical Immunology, 109, 250 265, 2003.

Liu, Y., J. A. Sarnat, V. Kilaru, D. J. Jacob, and P. Koutrakis, Estimating ground-level PM2.5 in the eastern United States using satellite remote sensing, Environ. Sci. Technol., 39, $32693278,2005$.

Martin, R.V.. et al., Interpretation of TOMS observations of tropospheric ozone with a global model and in-situ observations, J. Geophys. Res., 10\%, 4351, doi:10.1029/2001JD001480, 2002.

Martin, R.V., D.J. Jacob, R.M. Yantosca, M. Chin, and P. Ginoux, Global and regional decreases in tropospheric oxide emissions constrined by space-based observations of NO2 columns, J. Geophys. Res., 108, 4097, doi:10.1029/2002JD002622, 2003.

Mishchenko, M. I., and A. A. Lacis, B. E. Charlson, and L. D. Tavis, Nonsphericity of dust-like tropospheric aerosols: Implications for aerosl remote sensing and climate modeling, Geophys. Res. Lett., 22, 1077-1080, 1995.

Nakajima, T., M. Tanaka, and T. Yamauchi, Retrieval of the optical properties of aerosols from aureole and extinction data, Appl. Opt., 22, 2951-2959, 1983.

Natraj, V., R. Spurr, H. Boesch, Y. Jiang, and Y. Yung, Evaluation of errors in neglecting polarization in the forward modeling of $\mathrm{O} 2 \mathrm{~A}$ band measurements from space, with relevance to $\mathrm{CO} 2$ column retrieval from polarization sensitive instruments, JQSRT, in press, 2006 .

Park, R.J., D.J. Jacob, M. Chin, and R.V. Martin, Sources of carbonaceous aerosols over the United States and implications for natural visibility conditions, J. Geophys. Res., 108, 
4355, doi:10.1029/2002JD003190, 2003.

Pope, C. A., III, R. T. Burnett, M. J. Thun, E. E. Calle, D. Krewski, K. Ito, and G. D. Thurston (2002), Lung cancer, cardiopulmonary mortality, and long-term exposure to fine particulate air pollution, J. Am. Med. Assoc., 8488, doi:10.1029/2002JD002408, 2002.

Prospero, J.M. and D.L. Savoie, Effect of continental sources of nitrate concentrations over the Pacific Ocean, Nature, 339, 687-689, 1989.

Ramanathan, V., et al., Warming trends in Asia amplified by brown cloud solar absorption, Nature, 448, 575-578, 2007.

Spurr, R.J.D., T.P. Kurosu, and K.V. Chance, A linearized discrete ordinate radiative transfer model for atmospheric remote sensing retrieval, J. Quant. Spectrosc. Rad. Trans., 68, 689-735, 2001.

Tanre, D., Y.J. Kaufman, M. Herman, and S. Matoo, Remote sensing of aerosol properties over oceans using the MODIS/EOS spectral radiances, J. Geophys. Res., 102, 16971-16988, 1997.

Torres, O., P.K. Bhartia, J.R. Herman, Z. Ahmad, and J. Gleason, Derivation of aerosol properties from satellite measurements of backscattered ultraviolet radiation theoretical basis, J. Geophys. Res., 103, 17099-17110, 1998.

Wang, J., and S.A. Christopher, Intercomparison between satellite-derived aerosol optical thickness and PM2.5 mass: Implications for air quality studies, Geophys. Res. Lett., 30, 2095, doi:10.1028/2003GL018174.

Zender C. S., H. Bian, D. Newman, Mineral Dust Entrainment and Deposition (DEAD) model: Description and 1990s dust climatology, J. Geophys. Res., 108 (D14), 4416, 
doi:10.1029/2002JD002775, 2003.

Zhang, J., J. S. Reid, and B. N. Holben, An analysis of potential cloud artifacts in MODIS over ocean aerosol optical thickness products, Geophys. Res. Lett., 32, L15803, doi:10.1029/2005GL023254, 2005.

Zhang, Y., B. Pun, K. Vijayaraghavan, S.-Y. Wu, C. Seigneur, S. N. Pandis, M. Z. Jacobson, A. Nenes, and J. H. Seinfeld, Development and application of the Model of Aerosol Dynamics, Reaction, Ionization, and Dissolution (MADRID), J. Geophys. Res., 109, D01202, doi:10.1029/2003JD003501, 2004.

Received 

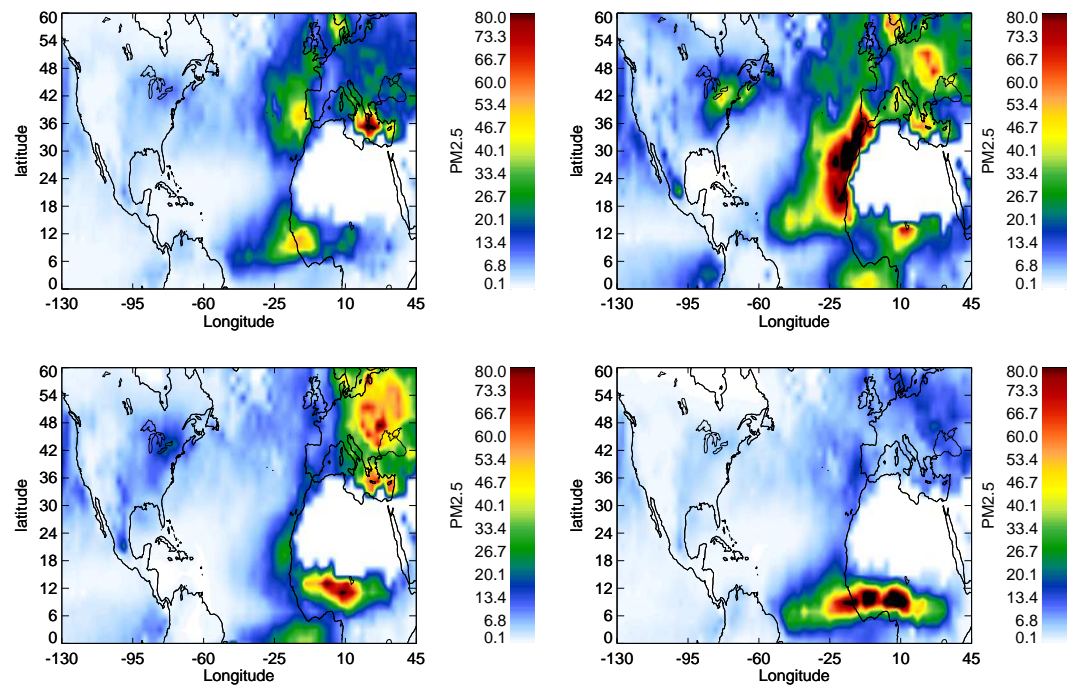

Figure 1. Seasonally averaged PM2.5 (unit: $\mu \mathrm{g} / \mathrm{m} 3$ ) from MODIS/MISR and GEOS-Chem chemical transport model for March-May 2003 (MAM, upper left panel), June-August 2003 (JJA, upper right panel), September-November 2003 (SON, lower left panel), and December 2002 to February 2003 (DJF, lower right panel).

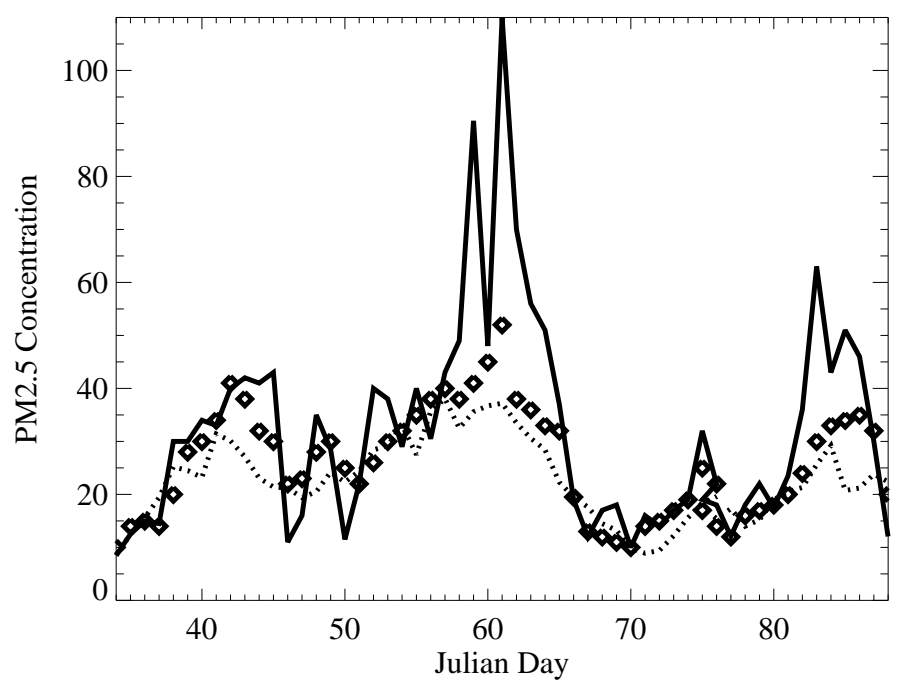

Figure 2. The inter-comparison of PM 2.5 (unit: $\mu \mathrm{g} / \mathrm{m} 3$ ) daily mean between measurements at the Melpitz, Germany and retrievals for 3 February 2003 - 31 March 2003 The solid line represents the measurements. The dotted line represents the GEOS-Chem model simulations. The diamond symbol represents the retrievals. 


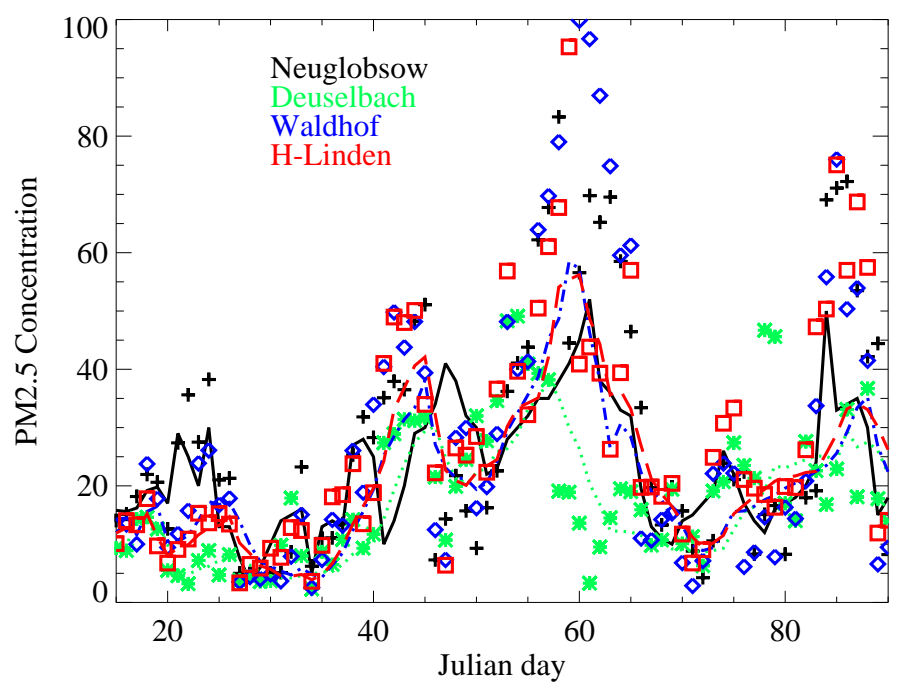

Figure 3. The inter-comparison of PM2.5 (unit: $\mu \mathrm{g} / \mathrm{m} 3$ ) daily mean between measurements at the Neuglobsow, Deuselbach, Waldhof, H-Linden in Germany and retrievals for 15 January 2003 - 31 March 2003. The lines represent the retrievals. The symbols represent the measurements.

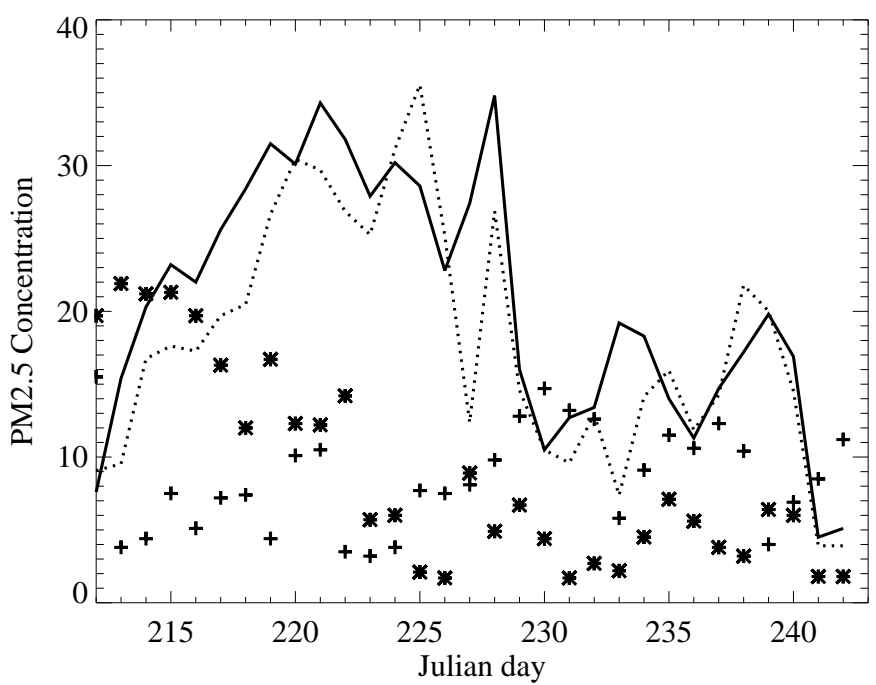

Figure 4. The inter-comparison of PM2.5 (unit: $\mu \mathrm{g} / \mathrm{m} 3$ ) measured in August at the Schauinsland, Germany for year 2002, 2003 and 2004 shown in the plus symbols, the solid line and the asterisk symbles respectively. The dotted line represents the retrieval. 


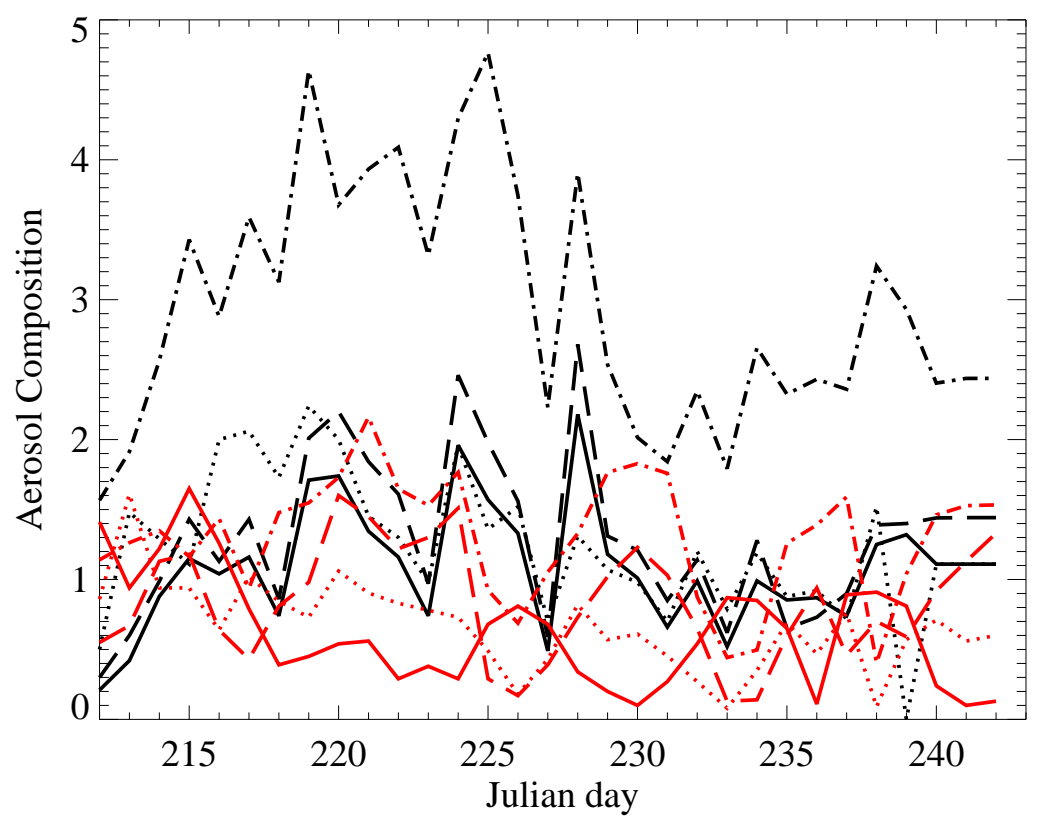

Figure 5. The contribution of aerosol species to PM2.5 (unit: $\mu \mathrm{g} / \mathrm{m} 3$ ) retrieved in August, 2003 and 2004 at the Schauinsland, Germany shown in black and red colors respectively. Solid, ammonium nitrate; dotted, black carbon; long dashes, sulphate; dash dot, mineral dust. 

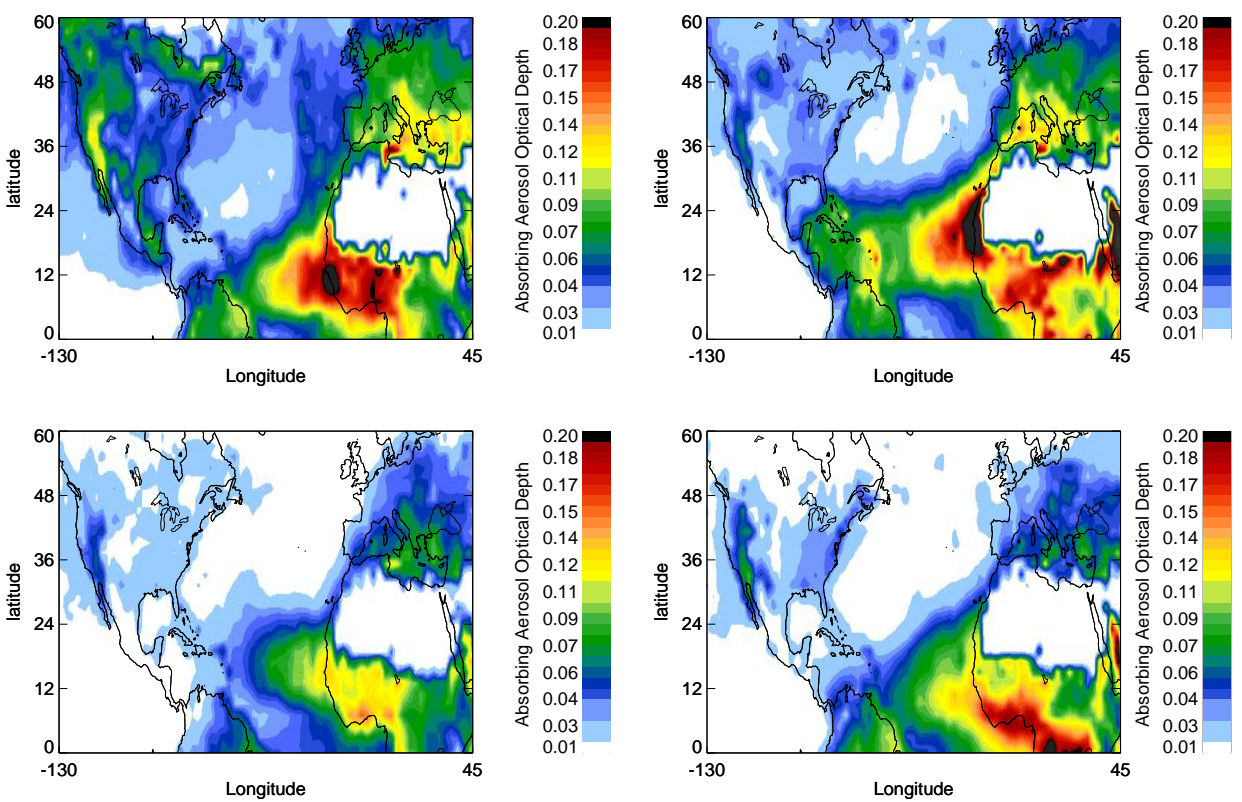

Figure 6. Seasonally averaged absorbing aerosol optical depth from MODIS/MISR and TOMS measurements for March-May 2003 (MAM, upper left panel), June-August 2003 (JJA, upper right panel), September-November 2003 (SON, lower left panel), and December 2002 to February 2003 (DJF, lower right panel). 


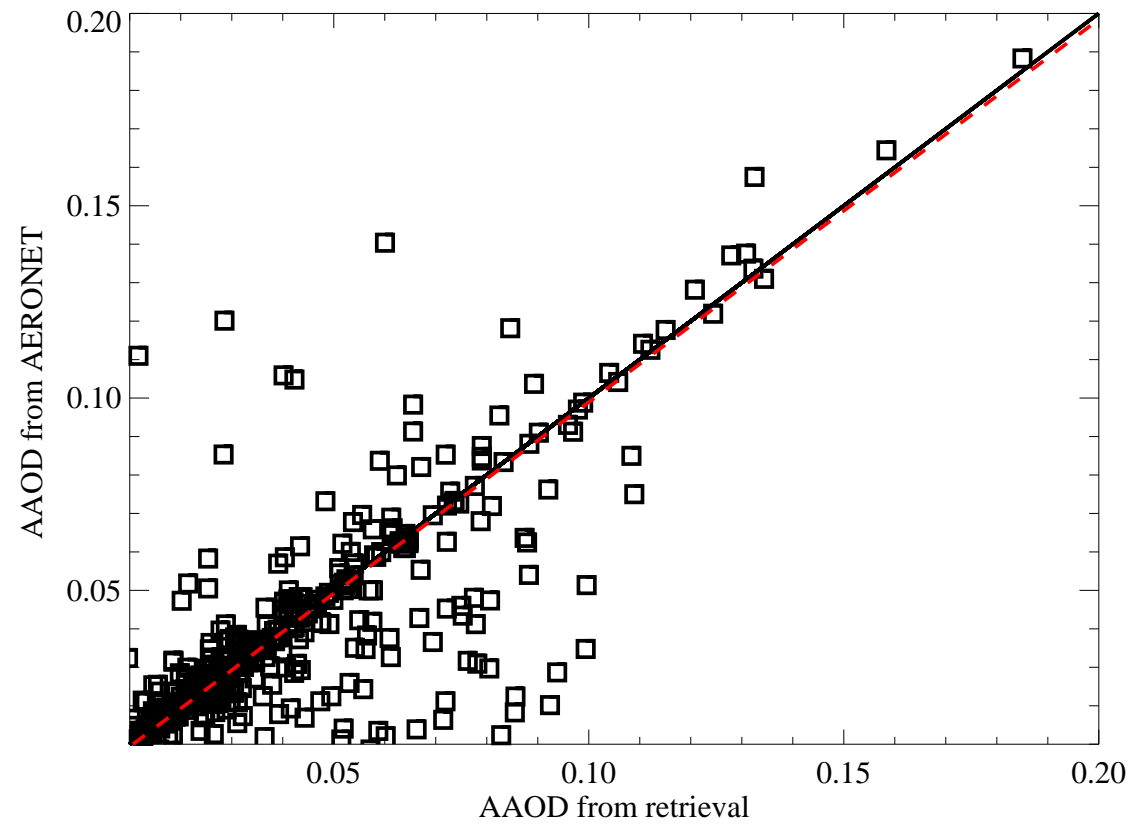

Figure 7. The inter-comparison of absorbing aerosol optical depth (AAOD) between AERONET data and retrievals for June 2003 - August 2003. The solid line represents the $\mathrm{y}=\mathrm{x}$ line. The dashed line was calculated with organic regression [Hirsh and Gilroy, 1984]. 
Table 1. Aerosol physical and optical properties used in this study

\begin{tabular}{|l|l|l|l|l|}
\hline \hline Aerosol Component & $r_{g}(\mu \mathrm{m})$ & $\sigma_{g}$ & Density $\left(\mathrm{gcm} \mathrm{cm}^{-3}\right)$ & Refractive Index $($ at $0.55 \mu \mathrm{m})$ \\
\hline Sulfate & 0.07 & 1.8 & 1.7 & $1.54-1.0 \mathrm{x} 10^{-7} \mathrm{i}$ \\
\hline Nitrate & 0.1 & 1.8 & 1.7 & $1.46-4.2 \times 10^{-8} \mathrm{i}$ \\
\hline Black carbon & 0.01 & 2.0 & 1.0 & $1.75-4.6 \mathrm{x} 10^{-1} \mathrm{i}$ \\
\hline Organic carbon & 0.02 & 2.0 & 1.8 & $1.48-0.002 \mathrm{i}$ \\
\hline Dust & 0.4 (acc.);4.0 (coa.) & 2.0 & 2.6 & $1.53-0.008 \mathrm{i}$ \\
\hline Sea salt & 0.4 (acc.);3.5 (coa.) & 2.0 & 2.2 & $1.38-3.7 \times 10^{-9} \mathrm{i}$ \\
\hline
\end{tabular}

